\title{
Investigating hepatitis $B$ immunity in patients presenting to a paediatric haematology and oncology unit in South Africa
}

\author{
A Büchner, MB ChB, DCH (SA), FCPaed (SA); F E Omar, MB ChB, FCPaed (SA), Cert Med Oncol (Paed); \\ J Vermeulen, MB ChB, FCPaed (SA), Cert Med Oncol (Paed); \\ D T Reynders, MB ChB, MRCPCH (Lond), FCPaed (SA), Cert Med Oncol (Paed)
}

Paediatric Haematology and Oncology Unit, Steve Biko Academic Hospital, Pretoria, South Africa

Corresponding author: A Büchner (ane.buchner@up.ac.za)

Background. Hepatitis B is an important public health concern in South Africa (SA). The hepatitis B virus (HBV) vaccine was introduced into the South African Expanded Programme on Immunisation (EPI-SA) in 1995. There is no 'catch-up' programme in place. The duration of protection after hepatitis B vaccination in the SA population is unknown. Waning of vaccine-induced immunity leaves people at risk of acquiring hepatitis $B$ infection in settings where the prevalence of infection is high and horizontal transmission is likely.

Objective. To assess immunity to HBV in patients at presentation to a paediatric haematology and oncology unit.

Methods. An audit of hepatitis profiles was done of all new patients seen in the unit from January 2012 to December 2013. Patients were classified as immune (antibody levels to hepatitis B surface antigen (anti-HBs) $>100 \mathrm{mIU} / \mathrm{ml}$ ), low immune (anti-HBs $10-100 \mathrm{mIU} / \mathrm{ml}$ ) and not immune (anti-HBs $<10 \mathrm{mIU} / \mathrm{ml}$ ).

Results. Of the 210 patients included (median age 6.5 years), 84 (40.0\%) had no immunity to hepatitis B despite presumed vaccination as part of the EPI schedule. Six patients tested positive for hepatitis B core antibody (anti-HBc), consistent with previous infection. No patients had active hepatitis B infection (hepatitis B surface antigen-positive). Most human immunodeficiency virus (HIV)-infected patients were not immune to $\mathrm{HBV}(80.0 \%)$.

Conclusion. A significant number of children in SA are not immune to hepatitis B despite vaccination being part of the EPI-SA. Combined passive-active immunisation should be considered for all oncology patients in settings where exposure to HBV is possible. Consideration should also be given to offering booster vaccination to the population as a whole.

S Afr Med J 2014;104(9):628-631. DOI:10.7196/SAMJ.7952

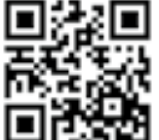

The prevalence of hepatitis B virus (HBV) infection in patients with haematological malignancies is higher than that in the general population. ${ }^{[1]}$ The higher prevalence can be explained by the immune suppression induced by cytotoxic chemotherapy, which leads to increased susceptibility. ${ }^{[2,3]}$ Immune suppression may also lead to reactivation of occult HBV infection and increased HBV replication.

Horizontal transmission of HBV during early childhood is considered the main route of infection in developing countries. ${ }^{[4-9]}$ This transmission of HBV is unrelated to sexual, perinatal or parenteral exposure. Transmission between family members may occur in communities with poor socioeconomic and hygienic conditions, and with long periods of close interaction. ${ }^{[10]}$ The mode of horizontal transmission is uncertain, but contact with body fluids, mainly saliva, is a prominent feature. ${ }^{[7,8,11]}$

Vaccination is recommended for individuals at risk of HBV infection as a result of percutaneous or mucosal exposure to blood or blood products, as well as for those at risk of severe hepatitis B infection. ${ }^{[5]}$ Patients in oncology units, transplant candidates, and individuals receiving frequent blood or blood product transfusions should be vaccinated. ${ }^{[1,5]}$

From April 1995, the HBV vaccine was included in the South African Expanded Programme of Immunisation (EPI-SA) at 6, 10 and 14 weeks of age. No 'catch-up' immunisation of older age groups was implemented. ${ }^{[4]}$ In 2010, $94 \%$ of children in South Africa (SA) were reported to be fully immunised against HBV (received three doses) in their first year of life. ${ }^{[6,8]}$ However, according to the World Health Organization (WHO), only $56 \%$ of babies in SA received all three doses. ${ }^{[8]}$ Current reports on children vaccinated against HBV in SA have found a low prevalence of hepatitis B surface antigen (HBsAg) positivity, ranging from none in children with unknown HIV status to $2.7 \%$ in HIV-positive children. ${ }^{[8,9]}$

The effectiveness of the HBV vaccine is assessed by measuring antibody levels to HBsAg (anti-HBs) levels in the serum. Various studies conducted after the inclusion of HBV vaccine in the EPISA immunisation schedule have shown the vaccine to be highly immunogenic and effective. ${ }^{[8]}$ Protective levels of anti-HBs, defined as $>10 \mathrm{mIU} / 1$ in healthy, immune-competent children, ${ }^{[8]}$ were found in $78-87 \%$ of healthy children, with none or very few children positive for HBsAg or HBV DNA. The vaccine was also tested in babies with HIV infection, in whom it has proved to be less effective. For example, protective levels of anti-HBs achieved through immunisation were found in $78.1 \%$ of HIV-positive patients in comparison with $85.7 \%$ of HIV-negative patients. ${ }^{[8]}$

The duration of HBV-vaccine-induced immunity after primary immunisation during infancy is not known. ${ }^{[12,13]}$ Although specific antibody levels decline rapidly after vaccination, protection through immune memory is thought to extend into adulthood. The waning of vaccine-induced immunity could leave adolescents and adults at risk of HBV infection. ${ }^{[13]}$

\section{Objective}

This study reports on an audit of records of children presenting to a haematology and oncology unit. Our primary objective was to investigate serological evidence of previous exposure to HBV or vaccine immunity to $\mathrm{HBV}$ at first presentation. A secondary objective was to identify patients at risk of contracting hepatitis B infection 
through horizontal transmission. The overall aim of the study was to provide a basis on which a further preventive strategy could be developed if deemed necessary.

\section{Methods}

A hospital-based audit was done using patient records of all children who presented to the paediatric haematology and oncology unit at Steve Biko Academic Hospital (SBAH), a tertiary academic hospital in Pretoria, SA, during the period 1 January 2012 - 31 December 2013. Demographic data (age and gender) and diagnosis of each patient were documented on presentation. HBV serology results for all patients (irrespective of the diagnosis) were reviewed.

Serological screening for hepatitis A, B and $\mathrm{C}$ is routinely done on all new patients on presentation to the unit. Screening for $\mathrm{HBV}$ includes serological testing for $\mathrm{HBsAg}$, anti-HBs and antibodies to hepatitis B core antigen (anti- $\mathrm{HBc}$ ). Hepatitis $\mathrm{B}$ e-antigen (HBeAg) and antibodies to hepatitis $B$ e-antigen (anti-HBe) are only tested for when $\mathrm{HBsAg}$ is positive (in patients with hepatitis $\mathrm{B}$ infection). Immunoassays using Abbott ARCHITECT i2000 (Abbott Diagnostics, Germany) were used for $\mathrm{HBV}$ serological testing.

Anti-HBs levels of $>100 \mathrm{mIU} / \mathrm{ml}$ were defined as complete protection against hepatitis B infection, levels of $10-100 \mathrm{mIU} / \mathrm{ml}$ as partial protection and levels of $<10 \mathrm{mIU} / \mathrm{ml}$ as no protection. Antibody levels of $>100 \mathrm{mIU} /$ $\mathrm{ml}$ are recommended for ensuring protection against hepatitis B infection in immunecompromised patients. ${ }^{[14-17]}$

Data were analysed with SSPS version 21. All proportions are reported as percentages with $95 \%$ confidence intervals (CIs). Differences between proportions were compared using the $\chi^{2}$ test. A threshold of significance of $p=0.05$ was used for all analyses.

\section{Results}

A total of 210 patients who presented to our unit between 1 January 2012 and 31
December 2013 were included. None had received previous immunosuppressive therapy. Table 1 summarises the diagnoses and anthropometric data. Diagnoses were as follows: 41 (19.5\%) leukaemia, 31 (14.8\%) lymphoma (21 non-Hodgkin's lymphoma, 10 Hodgkin's lymphoma), 92 (43.8\%) solid tumours, and $46(21.9 \%)$ benign or nonmalignant haematological conditions. The solid tumour group did not include any patients with primary liver tumours (hepatoma, hepatoblastoma or hepatocellular carcinoma). Of the 210 patients, 25 (11.9\%) were HIV-infected, and of these eight (32.0\%) were newly diagnosed on presentation to the unit. There were 130 boys and 80 girls in the study group. The median age of the study group as a whole was 6.5 years (range 3 weeks - 17.6 years), that of the leukaemia/ lymphoma group 7.3 years (range 4 weeks 16.7 years), that of the solid tumour group 4.9 years (range 3 weeks - 17.6 years), and that of the group with benign or non-malignant haematological conditions 7.9 years (range 3 weeks - 15.7 years)
Active hepatitis B infection (HBsAg) was not detected in any of the patients during screening at the time of presentation to the unit. Six patients $(2.9 \%)$ had evidence of previous infection with anti-HBc detected in serum, but no current active infection (HBsAg-negative). One of the six patients with evidence of previous infection was HIV-positive and not yet on antiretroviral treatment.

Of the 210 patients in the study, 84 (40.0\%; 95\% CI 33.3 - 47.0) were seronegative for HBV, and 78 (37.1\%; 95\% CI 30.6 - 44.0) had anti-HBs titres of $10-100 \mathrm{mIU} / \mathrm{ml}$, considered to be insufficient in a population of immune-compromised patients. Only 48 patients (22.9\%; 95\% CI 17.4 - 29.2\%) had anti-HBs titres $>100 \mathrm{mIU} / \mathrm{ml}$ and were therefore protected against acquiring $\mathrm{HBV}$ (Fig. 1). Of the $25 \mathrm{HIV}$-positive patients, 20 (80.0\%; 95\% CI 59.3 - 93.2) had no immunity to $\mathrm{HBV}$ (anti-HBs titres $<10 \mathrm{mIU} / \mathrm{ml}$ ) (Fig. 2). There was a significant difference in immunity against HBV between the 1 5 -years age group and the over-12 age group

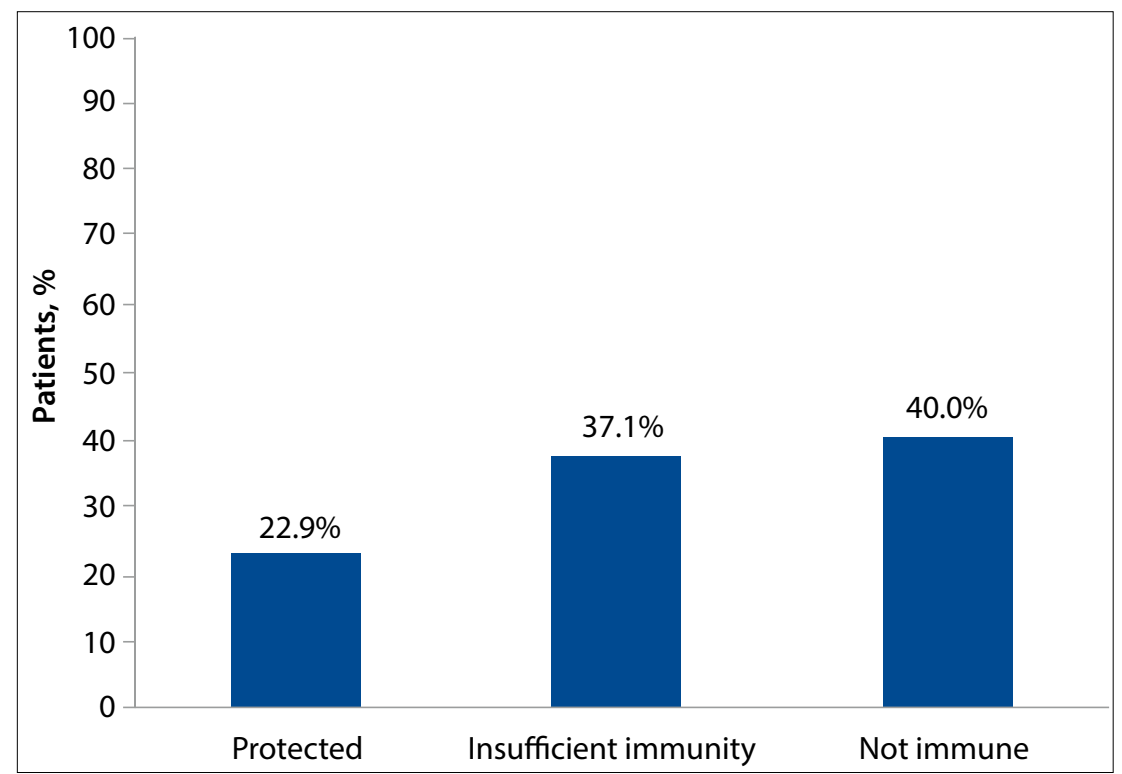

Fig. 1. Hepatitis $B$ immunity in the study group. (Protected = antibody levels to hepatitis $B$ surface antigen (anti-HBs) >100 mIU/ml; insufficient immunity = anti-HBs $10-100 \mathrm{mIU} / \mathrm{ml}$; not immune = anti-HBs $<10 \mathrm{mIU} / \mathrm{ml}$.)

Table 1. Diagnoses, gender and ages of children presenting to the paediatric haematology and oncology unit at SBAH $(N=210)$

\begin{tabular}{llllll}
\hline Characteristic & Leukaemia & Lymphoma & Solid tumours & Haematological conditions ${ }^{*}$ \\
\hline$N(\%)$ & $41(19.5)$ & $31(14.8)$ & $92(43.8)$ & $24(11.4)$ & Other $^{\dagger}$ \\
Males, $n(\%)$ & $24(58.5)$ & $26(83.9)$ & $51(55.4)$ & $17(70.8)$ \\
Age (years) & & & \\
$\quad$ Median & 5.8 & 10.3 & 4.9 & 7.9 \\
$\quad$ Range & $0.1-16.7$ & $2.3-15.3$ & $0.1-17.6$ & $0.6-13.9$ \\
$\begin{array}{l}\text { SBAH = Steve Biko Academic Hospital. } \\
{ }^{*} \text { Non-malignant haematological conditions include severe aplastic anaemia and sickle cell anaemia. }\end{array}$ \\
'Include benign eye conditions and healthy sibling donors.
\end{tabular}


$(p=0.005)$. In the age group $1-5$ years, 26 of 71 patients $(36.6 \%$; 95\% CI 25.5 - 48.9) had sufficient immunity (anti-HBs titres $>100 \mathrm{mIU} / \mathrm{ml}$ ), while in the over-12 age group only four of 40 (10.0\%; 95\% CI 2.8 23.7) did so. In the $<1$-year age group, five infants were $<8$ weeks of age and had therefore not received the first dose of HBV vaccine and had no protective immunity.

In the group with benign or nonmalignant haematological conditions, 12 of the 46 patients (26\%; 95\% CI 14.2 - 41.0) had anti-HBs levels of $>100 \mathrm{mIU} / \mathrm{ml}$, and in the leukaemia/lymphoma group only nine of 72 patients (12.5\%; 95\% CI 5.9 - 22.4) did so (Fig. 3).

\section{Discussion}

None of the patients in this study had active hepatitis $\mathrm{B}$ infection at initial screening and only six had evidence of previous infection. This rate of exposure to HBV is in keeping with the prevalence in SA (range $0-2.7 \%$ ) and reflects the protective effect of the immunisation received as part of the EPI-SA.

There were, however, a large number of patients $(77.1 \%)$ in the study with suboptimal anti-HBs titres of $<100 \mathrm{mIU} / \mathrm{ml}$. While there is no consensus about what level of antibodies against HBV is protective in immune-compromised patients, it is accepted that a level of $>10 \mathrm{mIU} / \mathrm{ml}$ after immunisation decreases the risk of a child with a normal immune response becoming a chronic carrier, despite the declining antibody level. ${ }^{[14-17]}$ The immune memory capable of protecting against chronic or symptomatic hepatitis B infection persists even after antibody levels decline to $<10 \mathrm{mIU} / \mathrm{ml}^{\left[{ }^{[12]}\right.}$ This immune memory has been shown to be protective in a large percentage of healthy children, but has not been assessed in patients on immunosuppressive therapy. The defects in immunological functioning caused by intensive chemotherapy may adversely affect the immune memory so that it may not be protective in childhood cancer patients. ${ }^{[18]}$ Despite being vaccinated as part of the EPI-SA, patients have acquired HBV in the paediatric oncology unit at SBAH. ${ }^{[7]}$

Previous studies have shown that HBV immunity declines with age. ${ }^{[6,8,12,13]}$ We were able to demonstrate a significant difference in levels of immunity to HBV in our patients. However, when comparing the 1 - 5-year age group with the over-12 group in this study, this difference in immunity may be overestimated when the size of the study population $(N=210)$ is taken into account. It is not possible to comment on the decline of HBV immunity in the study patients, because their HBV serology was not repeated.

Factors that increase susceptibility to $\mathrm{HBV}$ infection and reactivation in paediatric oncology patients may include frequent prolonged hospital admissions, severe immune-compromised states, a need for frequent blood product administration, and destruction of mucous membranes following cytotoxic chemotherapy. ${ }^{[1,2]}$ Active immunisation against HBV has been shown to be effective in patients with cancer. ${ }^{[3]}$

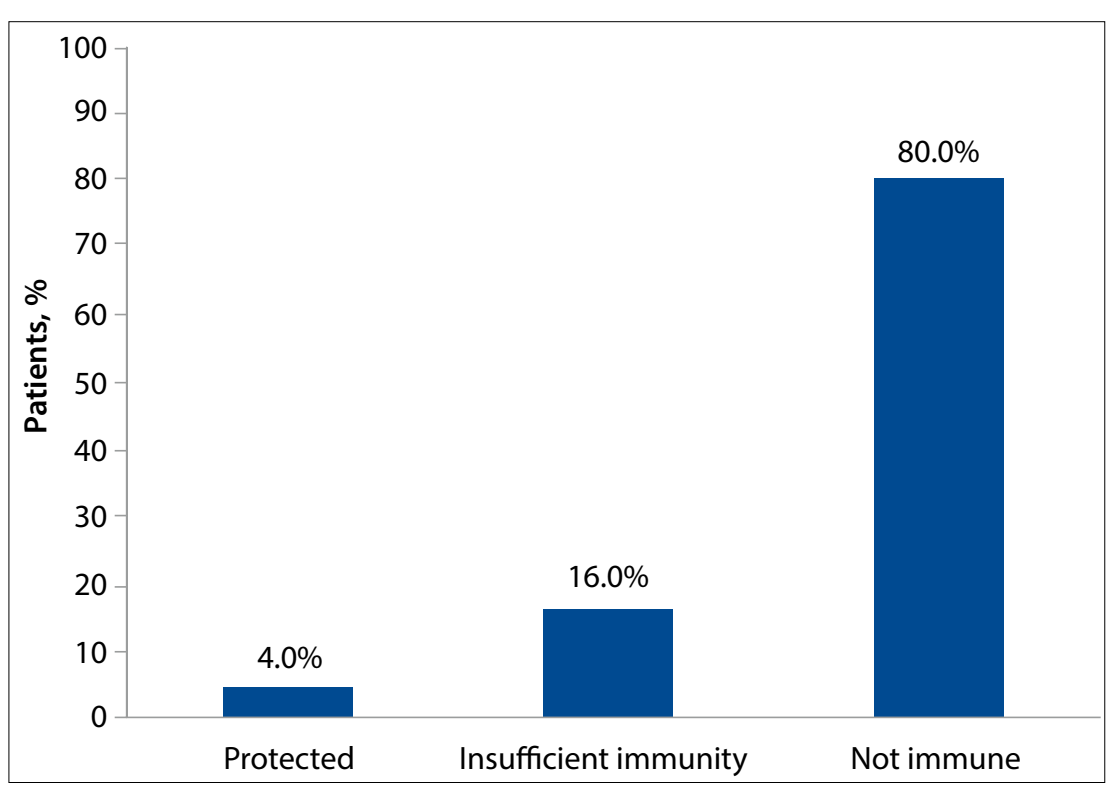

Fig. 2. Hepatitis B immunity in the subgroup of patients with HIV. (Protected = antibody levels to hepatitis $B$ surface antigen (anti-HBs) >100 mIU/ml; insufficient immunity = anti-HBs $10-100 \mathrm{mIU} / \mathrm{ml}$; not immune $=$ anti $-\mathrm{HBs}<10 \mathrm{mIU} / \mathrm{ml}$.)

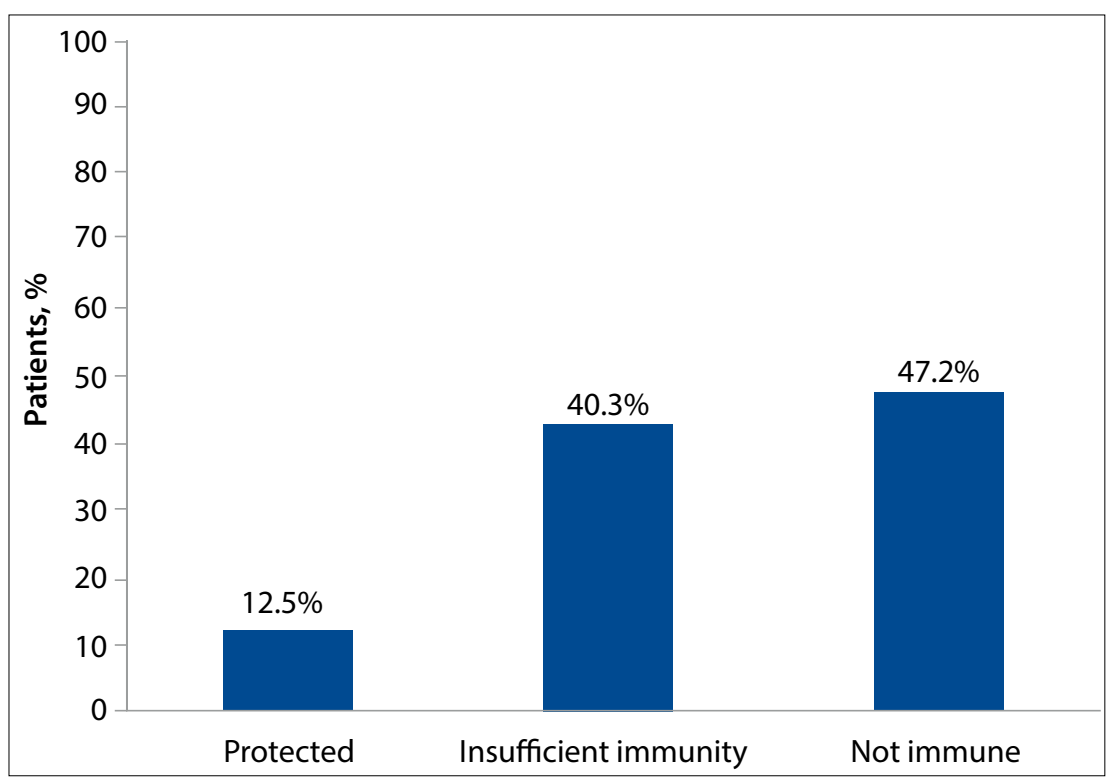

Fig. 3. Hepatitis $B$ immunity in the subgroup of patients with leukaemia/lymphoma. (Protected $=$ antibody levels to hepatitis $B$ surface antigen (anti-HBs) $>100 \mathrm{mIU} / \mathrm{ml}$; insufficient immunity = antiHBs $10-100 \mathrm{mIU} / \mathrm{ml}$; not immune $=$ anti-HBs $<10 \mathrm{mIU} / \mathrm{ml}$.) 
combined passive-active immunisation offered better protection against nosocomial HBV infection than active immunisation alone. The cost implication of offering solely passive prophylaxis during intensive chemotherapy of patients with leukaemia and non-Hodgkin's lymphoma led to discontinuation of this protocol and a recommendation for simultaneous passive and active immunoprophylaxis from the start of such therapy. ${ }^{[20]}$

HIV-positive patients in this study had very low levels of immunity to HBV. We could find no published reports on immunity to HBV of HIV-infected children compared with HIV-negative children. Among unimmunised adults, patients with AIDS were reported to have significantly decreased anti-HBs titres compared with a control group of HIV-negative adults. ${ }^{[22]}$ Adults with HBV/HIV co-infection have significantly higher HBV viral loads and for this reason are highly infectious, with an increased risk of transmitting HBV to close contacts and susceptible health workers. ${ }^{[22]}$ This is especially relevant and dangerous in a paediatric haematology and oncology unit where patients are continuously in close contact with each other and where there have been previous reports of HBV transmission. ${ }^{[7]}$ Patients with underlying HIV disease at the time of cancer diagnosis should be given combined passive-active immunisation to offer the best possible protection against $\mathrm{HBV}$ infection. ${ }^{[23]}$

Acute hepatitis infection caused by HBV could lead to delays in chemotherapy and for this reason worsen the patient's cancerrelated prognosis. ${ }^{[1]}$ Most children infected with HBV develop chronic hepatitis and therefore have an increased risk of developing cirrhosis and hepatocellular carcinoma. ${ }^{[3]}$ The complications of chronic hepatitis could potentially have a detrimental effect on the long-term morbidity of this group of patients.

\section{Conclusion}

A large group of patients attending our paediatric haematology and oncology unit did not have sufficient protective antibodies against $\mathrm{HBV}$ at first presentation, despite being vaccinated as part of the EPI-SA. These patients are at risk of hepatitis $B$ infection. Active surveillance and continued screening for HBV must be done at first presentation of all patients attending a paediatric haematology and oncology unit, and regularly during treatment and follow-up. A programme to immunise all seronegative patients against HBV should be implemented, and the response to immunisation documented. The use of combined passive-active immunisation should be encouraged, especially in children with haematological malignancies and HIV-infected children. Implementation of an effective screening and vaccination programme in the haematology and oncology unit should protect all patients from contracting HBV.

\section{References}

1. Lalazar G, Rund D, Shouval D. Screening, prevention and treatment of viral hepatitis B reactivation in patients with haematological malignancies. Br J Haematol 2007;136(5):699-712. [http://dx.doi. org $/ 10.1111 / j .1365-2141.2006 .06465 . x]$

2. Gigliotti AR, Fioredda F, Giacchino R. Hepatitis B and C infection in children undergoing chemotherapy or bone marrow transplantation. J Pediatr Hematol Oncol 2003;25(3):184-192. [http.// dx.doi.org/10.1097/00043426-200303000-00002]

3. Meral A, Sevinir B, Günay U. Efficacy of immunization against hepatitis B virus infection in children with cancer. Med Pediatr Oncol 2000;35(1):47-51. [http://dx.doi.org/10.1002/1096children with cancer. Med Pediatr Oncol 2000

4ew MC. Hepatitis B virus infection: The burden of disease in South Africa. South African Journal of 4. Kew MC. Hepatitis B virus infection: The bur
Epidemiology and Infection 2008;23(1):4-8.

5. Spearman CWN, Sonderup MW, Botha JF, et al. South African guideline for the management of chronic hepatitis B: 2013. S Afr Med J 2013;103(5):335-349. [http://dx.doi.org/10.7196/samj.6452]

6. François G, Dochez C, Mphahlele MJ, et al. Hepatitis B vaccination in Africa: Mission accomplished? South African Journal of Epidemiology and Infection 2008;23(1):24-28.

7. Willers E, Webber L, Delport R, Kruger M. Hepatitis B - a major threat to childhood survivors of leukaemia/lymphoma. J Trop Pediatr 2001;47(4):220-225. [http://dx.doi.org/10.1093/tropej/47.4.220] 8. Burnett RJ, Kramvis A, Dochez C, Meheus A. An update after 16 years of hepatitis B vaccination in South Africa. Vaccine 2012;30(S3):C45-C51. [http://dx.doi.org/10.1016/j.vaccine.2012.02.021]

9. Tsebe KV, Burnett RJ, Hlungwani NP, et al. The first five years of universal hepatitis B vaccination in South Africa: Evidence for elimination of HBsAg carriage in under 5-year-olds. Vaccine 2001;19(2829):3919-3926. [http://dx.doi.org/10.1016/S0264-410X(01)00120-7]

10. Doganci T, Uysal G, Kir T, et al. Horizontal transmission of hepatitis B virus in children with chronic . Doganci T, Uysal G, Kir T, et al. Horizontal transmission
hepatitis B. World J Gastroenterol 2005;11(3):418-420.

11. Kidd-Ljunggren $K$, Holmberg A, Bläckberg J, Lindqvist B. High levels of hepatitis B virus DNA in body fluids from chronic carriers. J Hosp Infect 2006;64(4):352-357. [http://dx.doi.org/10.1016/j. jhin.2006.06.029]

12. Hammitt LL, Hennessy TW, Fiore AE, et al. Hepatitis B immunity in children vaccinated with recombinant hepatitis B vaccine beginning at birth: A follow-up study at 15 years. Vaccine 2007;25(3940):6958-6964. [http://dx.doi.org/10.1016/j.vaccine.2007.06.059]

13. Chaves SS, Fischer G, Groeger J, et al. Persistence of long-term immunity to hepatitis B among adolescents immunized at birth. Vaccine 2012;30(9):1644-1649. [http://dx.doi.org/10.1016/j. vaccine.2011.12.106]

14. Jack AD, Hall AJ, Maine et al. What level of hepatitis B antibody is protective? J Infect Dis 1999;179(2):489-492. [http://dx.doi.org/10.1086/314578]

15. Hofmann F, Kralj N. Criteria for successful hepatitis B vaccination in adults: Results of a case study. Infection 2009;37(3):266-269. [http://dx.doi.org/10.1007/s15010-008-7410-y]

16. Tong NK, Beran J, Kee SA, et al. Immunogenicity and safety of an adjuvanted hepatitis B vaccine Tong NK, Beran J, Kee SA, et al. Immunogenicity and safety of an adjuvanted hepatitis B vaccine
in pre-hemodialysis and hemodialysis patients. Kidney Int 2005;68(5):2298-2303. [http://dx.doi. org/10.1111/j.1523-1755.2005.00689.x]

17. Han K, Shao X, Zheng H, et al. Revaccination of non- and low-responders after a standard three dose hepatitis B vaccine schedule. Hum Vaccin Immunother 2012;8(12):1845-1849. [http://dx.doi. org/10.4161/hv.21818]

18. Yu J, Chou AJ, Lennox A, et al. Loss of antibody titers and effectiveness of revaccination in postchemotherapy pediatric sarcoma patients. Pediatr Blood Cancer 2007;49(5):656-660. [http://dx.doi. org/10.1002/pbc.21277]

9. Mahoney FJ. Update on diagnosis, management, and prevention of hepatitis B virus infection. Clin Microbiol Rev 1999;12(2):351-366

20. Styczynski J, Wysocki M, Koltan S, Kurylak A. A nine-year experience of immunoprophylaxis against hepatitis B virus infection in children with cancer: Results from a single institution in Poland. J Hosp Infect 2001;48(4):298-303. [http://dx.doi.org/10.1053/jhin.2001.1017]

21. Somjee S, Pai S, Parikh P, et al. Passive active prophylaxis against hepatitis B in children with acute lymphoblastic leukaemia. Leuk Res 2002;26(11):989-992. [http://dx.doi.org/10.1016/S01452126(02)00044-9]

22. Mayaphi SH, Rossouw TM, Masemola DP, et al. HIV/HBV co-infection: The dynamics of HBV in South African patients with AIDS. S Afr Med J 2012;102(3):157-162.

23. Van den Berg R, van Hoogstraten I, van Agtmael M. Non-responsiveness to hepatitis B vaccination in HIV seropositive patients: Possible causes and solutions. AIDS Rev 2009;11(3):157-164.

Accepted 2 April 2014 